\title{
Involvement of upregulation of miR-2I0 in a rat epilepsy model
}

\author{
This article was published in the following Dove Press journal: \\ Neuropsychiatric Disease and Treatment \\ 13 July 2016 \\ Number of times this article has been viewed
}

\section{Licheng Chen \\ Hao Zheng \\ Shimeng Zhang}

Neurological Department of Internal Medicine, Linyi People's Hospital of Shandong Province, Linyi, People's Republic of China
Correspondence: Hao Zheng Neurological Department of Internal Medicine, Linyi People's Hospital of Shandong Province, 27 Eastern of Jiefang Road, Linyi, Shandong, 276000, People's Republic of China Tel +86 I379298 8030 Email haozheng5I@sina.com
Abstract: Epilepsy is a common type of neurological disorder with complex etiology. The mechanisms are still not clear. MicroRNAs are endogenous noncoding RNAs with many physiological activities. Multiple microRNAs were abnormally expressed in status epilepticus, including miR-210. In this study, we applied lithium chloride and pilocarpine to induce epileptic activity and aimed to disclose the potential mechanisms. Our data showed that miR-210 was significantly upregulated in hippocampus one day after modeling $(P<0.05$ vs control $)$ and the high expression of miR-210 lasted for at least 30 days. By contrast, $\gamma$-aminobutyric acid (GABA) level significantly decreased concurrently after modeling ( $P<0.05$ vs control). To question whether miR-210 could be a potential therapeutic target for epilepsy, miR-210 inhibitor was administrated through intrahippocampal injection after epilepsy modeling. Our data showed that morphological changes of hippocampal neurons and apoptosis triggered by epilepsy were mitigated by miR-210 inhibition. More importantly, the expressions of GABA-related proteins, including GABA A receptor $\alpha 1$, glutamate decarboxylase, and GABA transporter 1, were significantly elevated after epilepsy modeling in both mRNA and protein levels 3 days postmodeling ( $P<0.05$ vs control), which were mitigated by miR-210 inhibitor treatment ( $P<0.05$ vs model). In addition, epilepsy-induced upregulation of GABA transaminase was alleviated by miR-210 inhibitor. Taken together, these data implicated potential roles of miR-210 in lithium chloridepilocarpine-induced epilepsy model and miR-210 could serve as a potential therapeutic target in status epilepticus.

Keywords: epilepsy, miR-210, $\gamma$-aminobutyric acid, glutamate decarboxylase, $\gamma$-aminobutyric acid transaminase

\section{Introduction}

Epilepsy is one common type of neurological disorder hallmarked by oversynchronization of neurons in the brain. Abnormal and excessive firing of the neurons leads to disorders of central nervous system. ${ }^{1}$ Epilepsy is an electrical disturbance related to abnormalities of behaviors, including awareness, sensation, and movement disorders. ${ }^{2,3}$ Recently, the incidence of epilepsy increased annually and has risen as the second largest nervous system disease. ${ }^{4}$ Therefore, it is now of particular significance to unveil the mechanisms and find a new therapeutic approach for epilepsy.

Accumulating studies have investigated the mechanisms of epilepsy. Basically, dysfunction of ion channels, abnormal expression of epilepsy genes, and imbalance release of neuronal transmitters are responsible for the epileptic activity. ${ }^{5-7} \gamma$-Aminobutyric acid (GABA) is the major inhibitory neurotransmitter and decrease of GABA will lead to oversynchronization, subsequent to epilepsy. ${ }^{8-10}$ Therefore, GABA receptors were considered as one of the therapeutic targets for epilepsy. GABA stimulates its receptors and activates the related ion channels. The synthesis and metabolism of GABA are 
also important. GABA is decarboxylated from glutamate by glutamate decarboxylase (GAD). Therefore, the level of GAD is important for GABA level. GABA transaminase (GABAT) regulates the conversion from GABA to glutamate and GABAT is negatively correlated with the level of GABA. In addition, GABA transporter 1 (GAT-1) and GAT-3 in neurons or glia could lead to intake of GABA from synaptic cleft and prohibit the binding of GABA to its receptors. ${ }^{11}$ Therefore, the approaches which have capacities to alter GABA receptors (GABAR), GAD, GABAT, and GAT-1 will to some extent control the epileptic activity.

MicroRNAs (miRNAs) are a group of endogenous noncoding RNAs which can specifically bind to 3 '-untranslated region of the targeted mRNA and function to inhibit the translation of the target protein. Recent studies have found a lot of tissue-specific miRNAs. ${ }^{12}$ As reported, nine miRNAs were upregulated and 15 miRNA were downregulated in status epilepticus. ${ }^{13}$ miR-210 was one of the upregulated miRNAs. However, the exact role of miR-210 performed in status epilepticus is not verified. Considering the importance of GABA and its related signaling pathway in epilepsy, we asked whether miR-210 mediated GABA or a related signaling pathway. This study would unveil the important roles of miR-210 performed in status epilepticus.

\section{Animal modeling and treatment}

Sprague-Dawley rats (8 weeks, half male and half female) were purchased from SLAC (Shanghai, People's Republic of China) (License: SCXK 2012-0002) and housed in a 12-hour light/dark cycle in a temperature of $23^{\circ} \mathrm{C} \pm 2{ }^{\circ} \mathrm{C}$ with food and water ad libitum. All animal-handling procedures were performed according to the Guide for the Care and Use of Laboratory Animals of the National Institutes of Health and followed the guidelines of the Animal Welfare Act. All animal experiments were approved by the Experimental Animal Ethical Committee of Linyi People's Hospital of Shandong Province. In all, 78 rats were used to produce an epilepsy model through intraperitoneal injection of $125 \mathrm{mg} / \mathrm{kg}$ lithium chloride $(\mathrm{LiCl})$ followed by an injection of $1 \mathrm{mg} / \mathrm{kg}$ atropine (20-24 hours later). ${ }^{14}$ Thirty minutes after atropine injection, the rats were intraperitoneally injected with $20 \mathrm{mg} / \mathrm{kg}$ pilocarpine. The behaviors were classified into four grades based on Racine standard and grade IV was supposed as successful modeling. Thirty minutes after continual epileptic activity, 10 $\mathrm{mg} / \mathrm{kg}$ diazepam was applied to inhibit epilepsy activity.

After modeling, the rats were used in two experiments: experiment 1 , time-dependent effects of epilepsy modeling on miR-210 and GABA expression; experiment 2, the therapeutic effect of miR-210 inhibition. In experiment 1 , the modeled rats were divided into 1 day (d), $3 \mathrm{~d}, 7 \mathrm{~d}, 14 \mathrm{~d}$, and $30 \mathrm{~d}$ subgroups ( $n=8$ in each group). Eight normal rats were used as control. In experiment 2 , the modeled rats were divided into control, epilepsy, epilepsy + vehicle, and epilepsy + miR-210 inhibitor groups ( $n=8$ in each group). The treatment group received 1 nmol miR-210 inhibitor (Shanghai Sangon, Shanghai, People's Republic of China) 2 hours after epilepsy modeling. The treatment was through intrahippocampal injection bilaterally for 3 consecutive days at a rate of $2 \mu \mathrm{L} / \mathrm{min}$. After injection, the needle was left for 10 minutes. By contrast, vehicle was delivered to the vehicle-treated group. The rats in the control $(n=8)$ and epilepsy groups received the same volume of saline. Three days after treatment, rats were anesthetized by $10 \%$ chloral hydrate. The bilateral hippocampus was collected and fixed in 4\% paraformaldehyde or kept in liquid nitrogen for the experiments to follow. GABA , receptor $\alpha 1\left(\mathrm{GABA}_{\mathrm{A}} \mathrm{R} \alpha 1\right)$, GAD, GAT-1, and GABAT expressions were detected by real-time polymerase chain reaction (PCR) and Western blotting. Apoptosis of hippocampal neurons was detected by Tunel assay.

\section{Tunel assay}

Tunel assay was used to detect apoptosis of hippocampal neurons following the instructions of the kit (Boster, Wuhan, People's Republic of China). Briefly, 3 days after treatment, the brains were collected and fixed in 4\% paraformaldehyde. After dehydration, the brain was sliced into $30 \mu \mathrm{m}$ sections. After standard procedures as described in the instructions of the assay kit, the images were taken under microscope (AF6000; Leica Microsystems, Wetzlar, Germany). Five fields in each image were quantified. The total cell numbers and tunel-positive cell numbers were quantified. The apoptotic rate $=$ tunel-positive cell numbers/total cell numbers $\times 100 \%$.

\section{Real-time PCR}

miR-210 and related gene expressions were measured by real-time PCR method. Total RNA was abstracted using a Trizol kit. The RNA purity was defined by the ratio of OD260 and OD280. The values between 1.7 and 2.0 were supposed as high purity of mRNA. The RNA was reversely transcripted into cDNA. PCR was carried out by real-time PCR (LightCycler 96, Hoffman-La Roche Ltd., Basel, Switzerland) according to the following procedure: $95^{\circ} \mathrm{C}$ initial denaturation 5 minutes, $95^{\circ} \mathrm{C}$ denaturation 30 seconds, $58^{\circ} \mathrm{C}$ annealing 30 seconds, and $72^{\circ} \mathrm{C}$ extension 30 seconds for 30 cycles. The expressions of target genes were calculated by ${ }^{-\Delta} \mathrm{CT}$ method. ${ }^{15}$ The primers (Shanghai Sangon) are listed in Table 1. 
Table I PCR primers used in this study

\begin{tabular}{|c|c|c|}
\hline Target genes & Primers $\left(5^{\prime}-3^{\prime}\right)$ & bp \\
\hline \multirow[t]{2}{*}{$\operatorname{miR}-210$} & Forward: AGCGTGCTGTGCGTGTGAC & 64 \\
\hline & Reverse: CAGTGCAGGGTCCGAGGTATT & \\
\hline \multirow[t]{2}{*}{$G A B A_{A} R \alpha I$} & Forward: AATGGGCGGATTGGTGTC & 108 \\
\hline & Reverse: TCATCTTGGGAGGGCTGT & \\
\hline \multirow[t]{2}{*}{ GAD } & Forward: TCTTTTCTCCTGGTGGTGCC & 391 \\
\hline & Reverse: TCATCTTGGGAGGGCTGT & \\
\hline \multirow[t]{2}{*}{ GAT-I } & Forward: ACGCTTCGACTTCCTCATGTCCTGT & 699 \\
\hline & Reverse: GAATCAGACAGCTTTCGGAAGTTGG & \\
\hline \multirow[t]{2}{*}{ GABAT } & Forward: GTGAAGGCGTTCCGTAGCTC & 159 \\
\hline & Reverse: TGAGCGCGGCATCTTCTT & \\
\hline \multirow[t]{2}{*}{ GAPDH } & Forward: AGCCACATCGCTCAGACA & 314 \\
\hline & Reverse: TGGACTCCACGACGTACT & \\
\hline
\end{tabular}

Abbreviations: bp, base pair; GABAT, GABA transaminase; GAD, glutamate decarboxylase; GAPDH, glyceraldehyde 3-phosphate dehydrogenase; GAT-I, GABA transporter I; PCR, polymerase chain reaction.

\section{Western blotting}

Hippocampi were obtained and lysed by radioimmunoprecipitation assay lysis buffer (Beyotime, Ningbo, People's Republic of China). Protein concentrations were determined using BCA protein assay kit (Beyotime). Equivalent amounts of proteins $(20 \mu \mathrm{g})$ were processed for sodium dodecyl sulfate-polyacrylamide gel electrophoresis and Western blotting. The primary antibodies used were GABA (1:100, ab17413; Abcam, Cambridge, MA, USA), GABA $R \alpha 1$ (1:100, 06-868; EMD Millipore, Billerica, MA, USA), GAD (1:100, ab26113; Abcam), GAT-1 (1:100, ab72448; Abcam), GABAT (1:100, ab108249; Abcam), and glyceraldehyde 3-phosphate dehydrogenase (1:100, ab9485; Abcam). After incubation with the primary antibodies overnight at $4{ }^{\circ} \mathrm{C}$, the membrane (NC; Bio-Rad Laboratories Inc., Hercules, CA, USA) was incubated with the second antibody. Electrochemiluminescence reagent was applied to enhance the staining. ChemiDocTM XRS (Bio-Rad Laboratories Inc.) was applied to scan the blots and analyze the density of the blots.

\section{Data analyses}

Data are presented as mean \pm standard deviation. All the statistical analyses were performed by SPSS 17.0 (SPSS Inc., Chicago, IL, USA). Two-group comparison was completed by Student's $t$-test. A $P$-value $<0.05$ was considered statistically significant.

\section{Results}

\section{Epilepsy modeling increased hippocampal miR-I 20 and decreased GABA expression}

Totally, 78 Sprague-Dawley rats were used to establish the epilepsy model. Among them, 67 animals were successfully modeled (grade IV) with a rate of $85.9 \%$. Seven animals below grade IV were excluded from the experiment. In addition, four animals died; the death rate was 5.1\%.

As shown in Figure 1A, hippocampal miR-210 was significantly upregulated after epilepsy modeling at $1 \mathrm{~d}, 3 \mathrm{~d}$, $7 \mathrm{~d}$, and $30 \mathrm{~d}$ time points. miR-210 expression peaked at the $3 \mathrm{~d}$ time point. By contrast, GABA expression was reduced correspondingly after epilepsy modeling (Figure 1B).

\section{miR-2 I 0 inhibitor mitigated epilepsy modeling-induced morphological changes of hippocampal neurons}

Epilepsy modeling increased miR-210 expression. Therefore, we applied miR-210 inhibitor to observe the effect of miR-210 inhibition on morphological changes of CA1 neurons in hippocampus. As shown in Figure 2A, miR-210

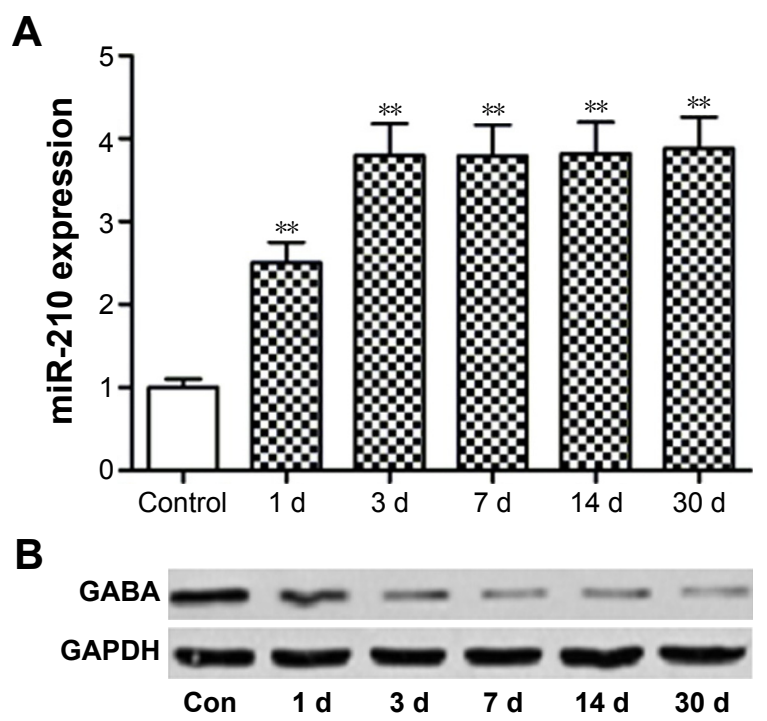

Figure I Epilepsy modeling increased miR-210 expression (A) and decreased GABA expression (B).

Note: $* * P<0.01$ compared with control.

Abbreviations: Con, control; GABA, $\gamma$-aminobutyric acid; GAPDH, glyceraldehyde 3-phosphate dehydrogenase. 


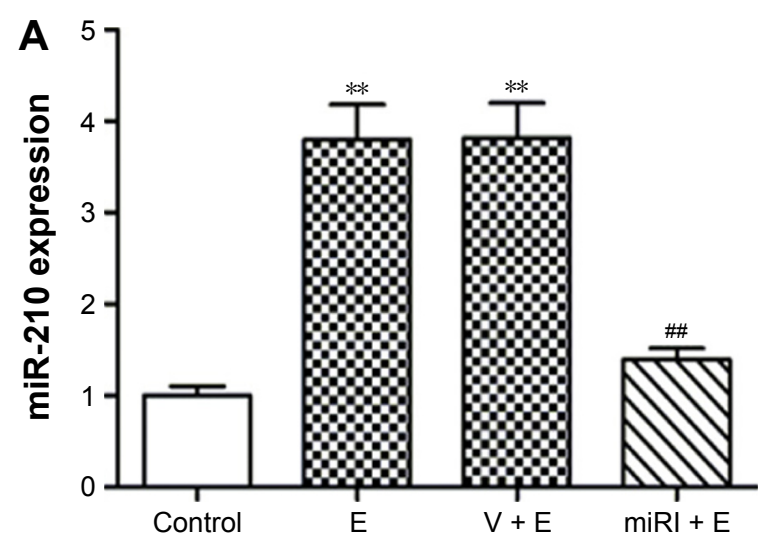

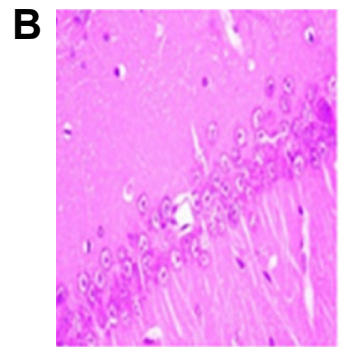

Control

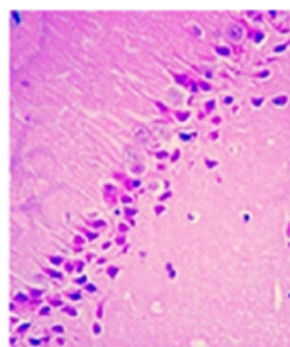

E

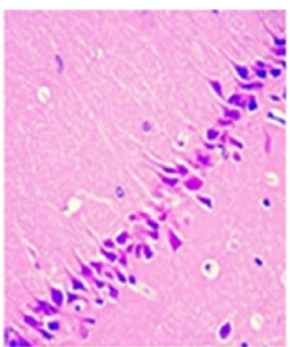

$V+E$

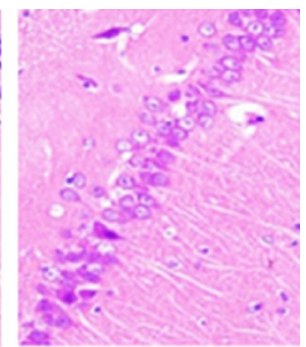

$\mathrm{miRI}+\mathrm{E}$

Figure 2 miR-210 inhibitor prohibited epilepsy-induced morphological changes.

Notes: (A) Intrahippocampal injection of miR-2I0 inhibitor reversed miR-210 level induced by epilepsy modeling. $* * P<0.01$ compared with control; ${ }^{*} P<0.01$ compared with E group. (B) Hematoxylin and eosin staining indicated that miR-2 10 inhibitor mitigated the morphological changes caused by epilepsy. Magnification $400 \times$.

Abbreviations: E, epilepsy; miRI $+E$, miR-2I0 inhibitor and epilepsy; $V+E$, vehicle and epilepsy.

inhibitor significantly reduced miR-210 expression in hippocampus, which indicated the efficacy of miR-210 inhibition. Hematoxylin and eosin staining was used to observe the morphological changes after drug treatments. Our results showed that pyramidal neurons in CA1 region were regularly arranged with a clear structure in the control group (Figure 2B). However, the neurons in model and vehicle-treated groups were irregularly arranged with a confused structure. The nuclei in the model group condensed as indicated by blue staining. Moreover, cells displayed swelling and were bulky in the epilepsy model group. By contrast, miR-210 inhibitor treatment remarkably mitigated the morphological abnormalities. The cell bodies of CA1 neurons in miR-210 inhibitor-treated group were arranged regularly and condensed nuclei disappeared.

\section{miR-2I0 inhibitor decreased the} apoptosis induced by epilepsy modeling

The apoptotic rates of pyramidal neurons in CA1 region were evaluated in different groups. As shown in Figure 3A, epilepsy modeling triggered typical apoptosis in CA1 region. By contrast, miR-210 inhibitor significantly decreased the apoptosis induced by epilepsy modeling (Figure 3B).

\section{miR-2 I 0 inhibitor altered the GABA signaling pathway-related protein expressions}

Compared with normal control, GABA $\mathrm{A} \alpha 1, \mathrm{GAD}$, and GAT-1 expressions were significantly downregulated in protein level after epilepsy modeling (Figure 4). By contrast, miR-210 treatment remarkably elevated the expressions of these proteins. GABAT was reduced in epilepsy model, but reversed by miR-210 treatment.

The gene expressions of $G A B A_{A} R \alpha 1, G A D, G A T-1$, and GABAT in mRNA level were also evaluated. As shown in Figure 5, GABA $A_{A} R \alpha 1, G A D$, and GAT-1 were significantly reduced in the model and negative control groups, which were blocked by miR-210 inhibitor treatment. GABAT expression was increased in the model and negative control groups, which were blocked by miR-210 treatment.

\section{Discussion}

Because the etiology of epilepsy is complex, a suitable epilepsy model would be beneficial for the elucidation of the epilepsy mechanisms. Epilepsy models have been produced by chemical substances or electrical stimulation. ${ }^{16}$ LiCl-pilocarpine-induced epilepsy model has similar 

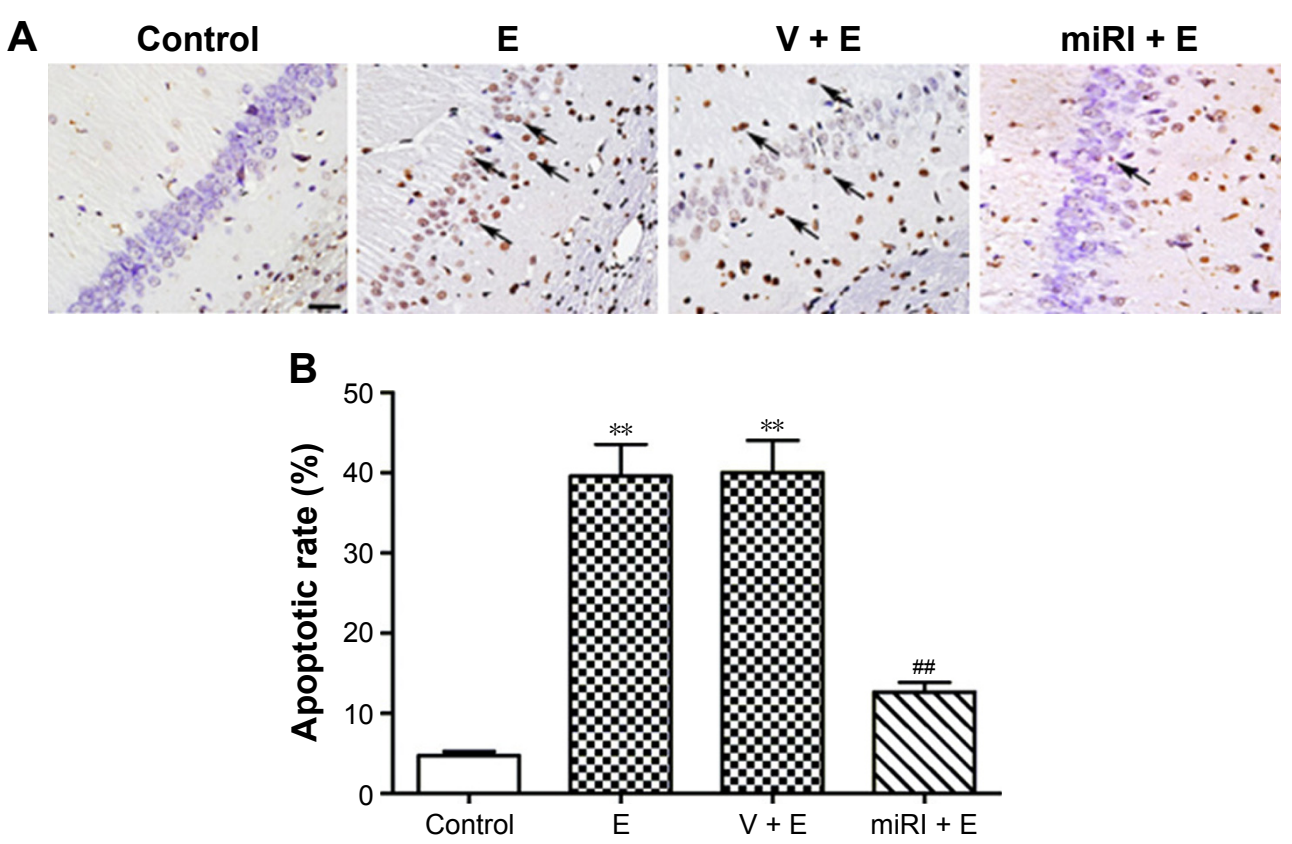

Figure 3 miR-210 inhibitor prohibited epilepsy-induced neuronal apoptosis.

Notes: (A) Apoptosis detected by Tunel assay with the arrows indicating apoptotic cells. Magnification $400 \times$. (B) Quantitative data of the apoptosis. $* * P<0.0$ I compared with control; $\#<<0.01$ compared with $E$ group.

Abbreviations: $E$, epilepsy; miRI $+E$, miR-2I0 inhibitor and epilepsy; $V+E$, vehicle and epilepsy.

phenotypes as the epileptic status in humans. ${ }^{17,18}$ In this study, we produced epilepsy activity in rats by injecting $\mathrm{LiCl}$ and pilocarpine. We found that $\mathrm{GABA}_{\mathrm{A}} \mathrm{R} \alpha 1, \mathrm{GAD}$, and GAT-1 expressions were decreased and GABAT expression increased after epilepsy modeling. Additionally, hippocampal neuronal apoptosis was observed in the CA1 region of hippocampus in our model. ${ }^{19}$ These characteristics are typical in status epilepticus.

Previous studies demonstrated that miRNAs perform critical roles in cancer, inflammation, vascular, and autoimmune diseases. ${ }^{20,21}$ As reported, miRNAs also function in neurological diseases, including stroke and cerebral ischemia. ${ }^{22,23}$ miRNAs also perform critical roles in kainic

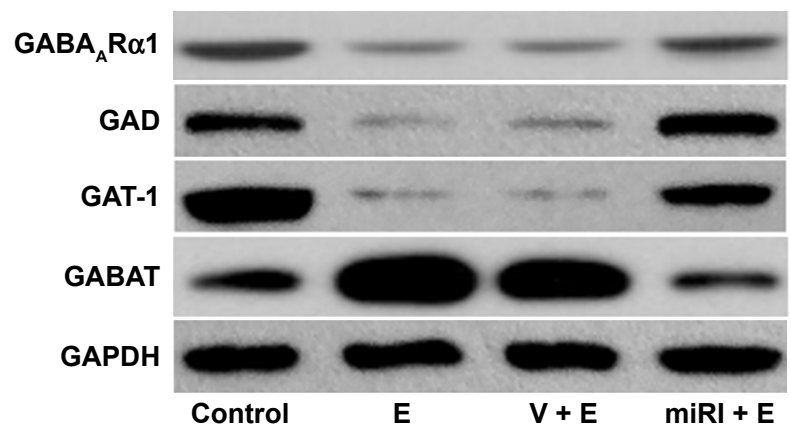

Figure 4 miR-210 inhibitor prohibited epilepsy-induced changes of GABA-related protein expressions.

Abbreviations: E, epilepsy; GABAT, GABA transaminase; GAD, glutamate decarboxylase; GAPDH, glyceraldehyde 3-phosphate dehydrogenase; GAT-I, GABA transporter I; miRI + E, miR-2IO inhibitor and epilepsy; V + E, vehicle and epilepsy. acid and pilocarpine-induced epilepsy. ${ }^{13}$ However, the roles of miR-210 performed in epilepsy are not well verified. miR-210 has extensive activities, especially in cell proliferation, apoptosis, DNA repairing, cell cycling, and vascular formation..$^{24,25} \mathrm{Hu}$ et al reported that nine miRNAs were upregulated in status epilepticus ${ }^{13}$ and miR-210 was one of the upregulated miRNAs. Consistently, we confirmed that miR-210 was upregulated 1 day after modeling and peaked at 3 days after modeling using real-time PCR. Moreover, the high expression of miR-210 lasted for at least 30 days. The continual expression of miR-210 indicated that miR-210 might be directly responsible for the status epilepticus.

Status epilepticus leads to ischemia, hypoxia, and swelling in hippocampus followed by an imbalanced release of excitatory amino acids. Calcium intracellular flux activates the caspase cascade and facilitates the production of oxidative stress, neuronal NO, and caspase- $3 .{ }^{26}$ Subsequently, cellular organs and skeletal proteins lose their functions and initiate apoptosis. We confirmed that epileptic activity triggered apoptosis of hippocampal neurons. More importantly, miR-210 inhibitor mitigated the apoptosis elicited by epileptic activity. The potential mechanisms might be related to the effects of miR-210 on mitochondrial metabolism and oxidative stress. ${ }^{27}$ Other miRNAs, such as miR-21, miR-34a, and miR-184, were also reported to regulate apoptosis in an epilepsy model. ${ }^{28}$ 

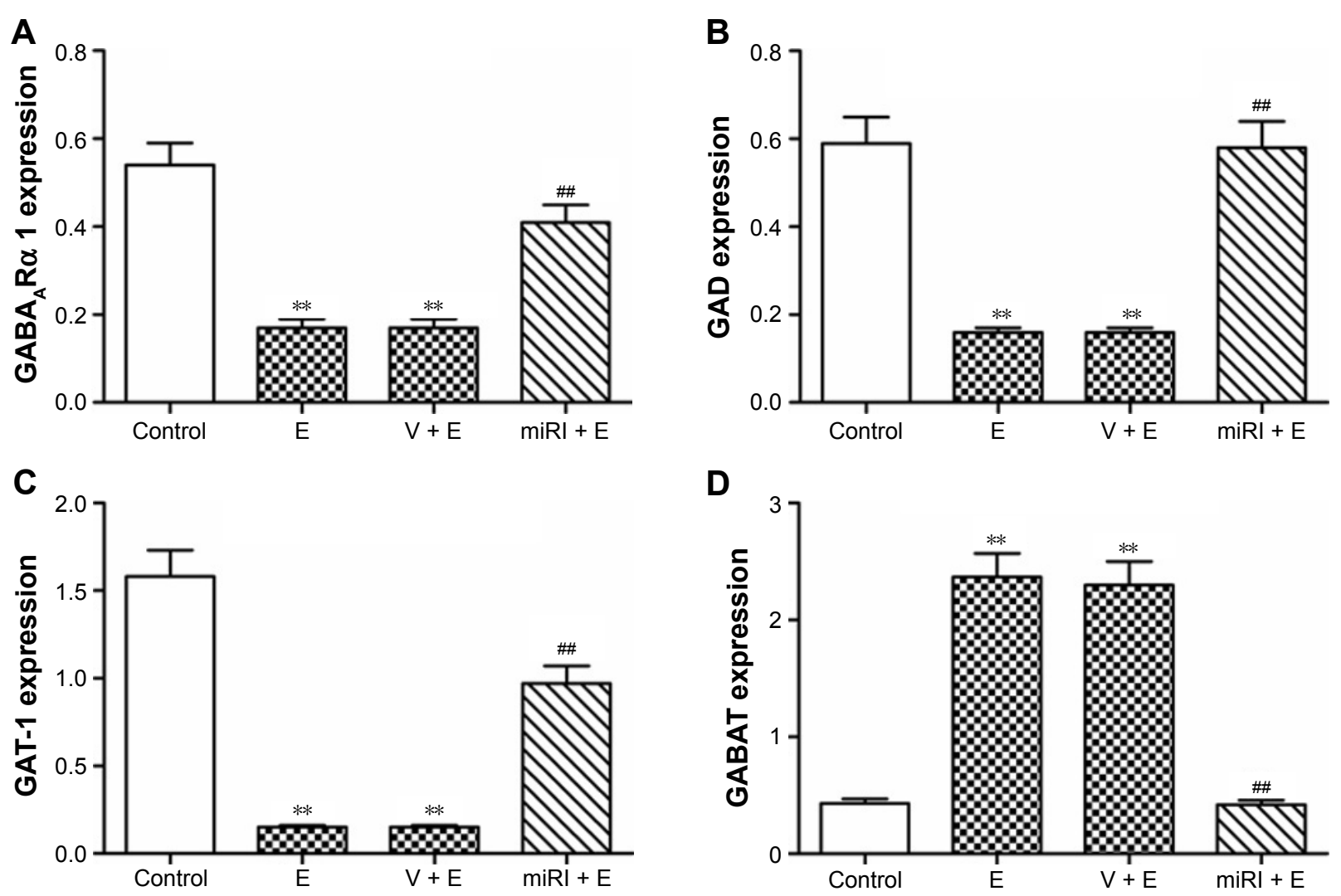

Figure 5 miR-210 inhibitor prohibited epilepsy-induced changes of GABA-related mRNA expressions.

Notes: ${ }^{* * P}<0.01$ compared with control; ${ }^{\# P} P<0.01$ compared with E group. (A) GABA R $\alpha$ I, (B) GAD, (C) GAT-I, (D) GABAT.

Abbreviations: E, epilepsy; GABAT, GABA transaminase; GAD, glutamate decarboxylase; GAT-I, GABA transporter I; miRI + E, miR-2I0 inhibitor and epilepsy; $V+E$, vehicle and epilepsy.

GABA is a common inhibitory neurotransmitter in the central nervous system. It is related to several neurological diseases and has functions in sedative and antianxiety medication. ${ }^{28}$ GABA exerts its functions through binding to GABA receptors. In our study, we found a decrease of $\mathrm{GABA}_{\mathrm{A}} \mathrm{R} \alpha 1$ after epilepsy modeling. There are three types of GABA receptors: $\mathrm{GABA}_{\mathrm{A}}$ receptor, $\mathrm{GABA}_{\mathrm{B}}$ receptor, and $\mathrm{GABA}_{C}$ receptor. $\mathrm{GABA}_{\mathrm{A}}$ receptor and $\mathrm{GABA}_{\mathrm{B}}$ receptor belong to similar ion receptors and function to inhibit the function of the central nervous system. Consistent with a previous study, ${ }^{29}$ GAD expression was also significantly decreased, while GABAT was increased in our epilepsy model. The major function of miRNAs is through regulating the translation of specific mRNA. In our case, GABA $R \alpha 1$, GAD, GABAT, and GAT-1 were all affected in the miR-210-treated group compared with the epilepsy model group. Moreover, the mRNA levels of these genes were influenced after epilepsy modeling. Therefore, miR-210 might not directly affect the expression of these genes. Nevertheless, as we discussed above, miR-210 could regulate oxidative stress and apoptosis. ${ }^{30}$
However, how miR-210 regulates the GABA signaling pathway deserves further investigation.

Considering the long-lasting and high expression of miR-210, it would be effective to inhibit miR-210 at the early and the later phases to treat status epilepticus. However, the treatment at the early phase might avoid the high injury caused by apoptosis of hippocampal neurons. Therefore, the exact time point (the early phase or later phase) of miR-210 should be screened. More related investigations describing the adverse effect of miR-210 treatment are required.

\section{Conclusion}

Our study firstly confirms the novel roles of miR-210 performed in epileptic activity. miR-210 inhibitor could effectively inhibit GABA ${ }_{A} R \alpha 1$, GAD, GAT-1, and increase GABAT expression to prohibit epilepsy modeling-induced hippocampal neuron apoptosis.

\section{Disclosure}

The authors report no conflicts of interest in this work. 


\section{References}

1. Behr C, Goltzene MA, Kosmalski G, Hirsch E, Ryvlin P. Epidemiology of epilepsy. Rev Neurol (Paris). 2016;172(1):27-36.

2. Nevalainen O, Simola M, Ansakorpi H, et al. Epilepsy, excess deaths and years of life lost from external causes. Eur J Epidemiol. Epub 2015 Oct 31 .

3. Lhatoo S, Noebels J, Whittemore V, Research NCfS. Sudden unexpected death in epilepsy: Identifying risk and preventing mortality. Epilepsia. 2015;56(11):1700-1706.

4. Covanis A, Guekht A, Li S, Secco M, Shakir R, Perucca E. From global campaign to global commitment: The World Health Assembly's Resolution on epilepsy. Epilepsia. 2015;56(11):1651-1657.

5. Jin $\mathrm{Y}$, Zhao $\mathrm{C}$, Chen $\mathrm{L}$, et al. Identification of novel gene and pathway targets for human epilepsy treatment. Biol Res. 2016;49(1):3.

6. Li J, Lin H, Niu F, et al. Combined effect between two functional polymorphisms of SLC6A12 gene is associated with temporal lobe epilepsy. $J$ Genet. 2015;94(4):637-642.

7. Baronas VA, Yang R, Vilin YY, Kurata HT. Determinants of frequencydependent regulation of Kv1.2-containing potassium channels. Channels (Austin). 2015;10(2):158-166.

8. Wahab A, Heinemann U, Albus K. Effects of gamma-aminobutyric acid (GABA) agonists and a GABA uptake inhibitor on pharmacoresistant seizure like events in organotypic hippocampal slice cultures. Epilepsy Res. 2009;86(2-3):113-123.

9. Treiman DM. GABAergic mechanisms in epilepsy. Epilepsia. 2001; 42(Suppl 3):8-12.

10. Mathews GC. The dual roles of GABA in seizures and epilepsy generate more excitement. Epilepsy Curr. 2007;7(1):28-30.

11. Jin XT, Galvan A, Wichmann T, Smith Y. Localization and function of GABA transporters GAT-1 and GAT-3 in the basal ganglia. Front Syst Neurosci. 2011;5:63.

12. Gautam V, Singh A, Singh S, Sarkar AK. An efficient LCM-based method for tissue specific expression analysis of genes and miRNAs. Sci Rep. 2016;6:21577.

13. Hu K, Xie YY, Zhang C, et al. MicroRNA expression profile of the hippocampus in a rat model of temporal lobe epilepsy and miR-34atargeted neuroprotection against hippocampal neurone cell apoptosis post-status epilepticus. BMC Neurosci. 2012;13:115.

14. Xin G, Shi W, Xu LX, Su Y, Yan LJ, Li KS. Serum BAFF is elevated in patients with IgA nephropathy and associated with clinical and histopathological features. J Nephrol. 2013;26(4):683-690.

15. Zhu G, Li J, He L, Wang X, Hong X. MPTP-induced changes in hippocampal synaptic plasticity and memory are prevented by memantine through the BDNF-TrkB pathway. Br J Pharmacol. 2015;172(9): 2354-2368.
16. Grone BP, Baraban SC. Animal models in epilepsy research: legacies and new directions. Nat Neurosci. 2015;18(3):339-343.

17. Peng WF, Ding J, Li X, Fan F, Zhang QQ, Wang X. N-methyl-daspartate receptor NR2B subunit involved in depression-like behaviours in lithium chloride-pilocarpine chronic rat epilepsy model. Epilepsy Res. 2016;119:77-85

18. Long L, Xiao B, Feng L, et al. Selective loss and axonal sprouting of GABAergic interneurons in the sclerotic hippocampus induced by LiCl-pilocarpine. Int J Neurosci. 2011;121(2):69-85.

19. Morimoto K, Fahnestock M, Racine RJ. Kindling and status epilepticus models of epilepsy: rewiring the brain. Prog Neurobiol. 2004;73(1): $1-60$.

20. Gurha P. MicroRNAs in cardiovascular disease. Curr Opin Cardiol. 2016;31(3):249-254.

21. Cherradi N. microRNAs as potential biomarkers in adrenocortical cancer: Progress and challenges. Front Endocrinol (Lausanne). 2015; 6:195.

22. Wang C, Ji B, Cheng B, Chen J, Bai B. Neuroprotection of microRNA in neurological disorders (Review). Biomed Rep. 2014;2(5):611-619.

23. Bourassa MW, Ratan RR. The interplay between microRNAs and histone deacetylases in neurological diseases. Neurochem Int. 2014;77: 33-39.

24. Wang Y, Ni H, Zhang W, Wang X, Zhang H. Downregulation of miR-210 protected bupivacaine-induced neurotoxicity in dorsal root ganglion. Exp Brain Res. 2016;234(4):1057-1065.

25. Tan W, Lim SG, Tan TM. Up-regulation of microRNA-210 inhibits proliferation of hepatocellular carcinoma cells by targeting YES1. World J Gastroenterol. 2015;21(46):13030-13041.

26. Pinton P, Giorgi C, Siviero R, Zecchini E, Rizzuto R. Calcium and apoptosis: ER-mitochondria $\mathrm{Ca} 2+$ transfer in the control of apoptosis. Oncogene. 2008;27(50):6407-6418.

27. Jiang Y, Li L, Tan X, Liu B, Zhang Y, Li C. miR-210 mediates vagus nerve stimulation-induced antioxidant stress and anti-apoptosis reactions following cerebral ischemia/reperfusion injury in rats. $J$ Neurochem. 2015;134(1):173-181.

28. Henshall DC. MicroRNAs in the pathophysiology and treatment of status epilepticus. Front Mol Neurosci. 2013;6:37.

29. Salazar P, Tapia R. Epilepsy and hippocampal neurodegeneration induced by glutamate decarboxylase inhibitors in awake rats. Epilepsy Res. 2015;116:27-33.

30. Hulsmans M, De Keyzer D, Holvoet P. MicroRNAs regulating oxidative stress and inflammation in relation to obesity and atherosclerosis. FASEB J. 2011;25(8):2515-2527.
Neuropsychiatric Disease and Treatment

\section{Publish your work in this journal}

Neuropsychiatric Disease and Treatment is an international, peerreviewed journal of clinical therapeutics and pharmacology focusing on concise rapid reporting of clinical or pre-clinical studies on a range of neuropsychiatric and neurological disorders. This journa is indexed on PubMed Central, the 'PsycINFO' database and CAS,

\section{Dovepress}

and is the official journal of The International Neuropsychiatric Association (INA). The manuscript management system is completely online and includes a very quick and fair peer-review system, which is all easy to use. Visit http://www.dovepress.com/testimonials.php to read real quotes from published authors. 